\title{
Pengaruh penerapan model pembelajaran kooperatif tipe mood, understand, recall, detect, elaborate, review terhadap hasil belajar siswa
}

(The influence of cooperative learning model mood, understand, recall, detect, elaborate, review type towards student learning outcomes)

\author{
Riksa Sugia Lestari', Sambas Ali Muhidin ${ }^{2 *}$ \\ ${ }^{1,2}$ Program Studi Pendidikan Manajemen Pendidikan Perkantoran, \\ Fakultas Pendidikan Ekonomi dan Bisnis, Universitas Pendidikan Indonesia, \\ Jl. Dr. Setiabudhi, No. 229 Bandung, Jawa Barat Indonesia \\ Email: sambas@upi.edu
}

\begin{abstract}
ABSTRAK
Model pembelajaran adalah salah satu faktor yang mempengaruhi hasil belajar siswa. Artikel ini membahas hasil penelitian kuasi eksperimen yang ditujukan untuk mengetahui pengaruh model pembelajaran kooperatif tipe Mood, Understand, Recall, Detect, Elaborate, Review terhadap hasil belajar 86 orang siswa di sebuah SMK di Kota Bandung pada mata pelajaran Administrasi Humas dan Protokol, kompetensi dasar Menguraikan Organisasi Profesi Humas. Dengan menggunakan non-equivalent control group design, hasil analisa data menunjukan bahwa model pembelajaran kooperatif tipe Mood, Understand, Recall, Detect, Elaborate, Review lebih cocok dalam meningkatkan hasil belajar siswa dalam mempelajari kompetensi dasar Menguraikan Organisasi Profesi Humas, dibandingkan dengan model Discovery Learning. Dengan demikian model pembelalajaran kooperatif tipe Mood, Understand, Recall, Detect, Elaborate, Review dapat menjadi salah satu alternatif bagi para guru Mata Pelajaran Adm. Humas dan Protokol dalam meningkatkan hasil belajar siswa pada mata pelajaran tersebut.
\end{abstract}

Kata Kunci: Suasana hati; Memahami; Penarikan; Deteksi; Rumit; Ulasan; Hasil Belajar

\begin{abstract}
Teaching and learning model is one of the factors influencing students' learning outputs. This article discusses results of a quasi-experimental study which aims to investigate the influence of Cooperative Learning Model Mood, Understand, Recall, Detect, Elaborate, Review Type on learning outputs of 86 vocational high school students, in the subject of Public Relations Administration and Protocol (in the competence of explain Public Relations Professional Organization). Using non-
\end{abstract}

Received: Agustus 2018, Revision: November 2018, Published: Januari 2019 
equivalent control group design, results of data analysis show that Cooperative Learning Model Mood, Understand, Recall, Detect, Elaborate, Review Type is more suitable to improve students' learning output in the competence of explain Public Relations Professional Organization, compare to Discovery Learning model. Thus, Cooperative Learning Model Mood, Understand, Recall, Detect, Elaborate, Review Type is worth using by teachers of the subject to improve the learning outputs of their students in this subject.

Keywords: Moo; Understand; Recall; Detect; Elaborate; Review; Learning Output

\section{PENDAHULUAN}

Hasil belajar merupakan hasil dari suatu interaksi tindak belajar dan mengajar (Dimyati dan Mudjiono, 2006, hlm. 3-4) yang mempunyai peranan penting dalam menentukan taraf keberhasilan suatu proses belajar mengajar atau untuk menentukan taraf keberhasilan baik menyangkut aspek kognitif, afektif, dan psikomotor (Susanto, hlm. 5) dalam sebuah program pengajaran (Syah, 2008). Hasil belajar siswa juga dapat menjadi alat penentu guru untuk dapat melanjutkan pembelajaran ke tahap selanjutnya. Hasil belajar dapat diketahui dengan pencapaian kompetensi dalam bentuk tes seperti Ulangan Harian, Ujian Tengah Semester (UTS), Ujian Akhir Semester (UAS).

Akan tetapi, terdapat permasalahan yang dihadapi dalam dunia pendidikan, yaitu masih rendahnya hasil belajar siswa. Di bawah ini merupakan hasil belajar yang diperoleh oleh siswa Jurusan Administrasi Perkantoran di salah satu SMK di Kota Bandung pada Mata Pelajaran Administrasi Humas dan Protokol selama 3 tahun terakhir:

Tabel 1.

Hasil Belajar Mata Pelajaran Adm. Humas dan Protokol

\begin{tabular}{|c|c|c|c|c|c|c|}
\hline $\begin{array}{c}\text { Tahun } \\
\text { Ajaran }\end{array}$ & Kelas & KKM & $\begin{array}{c}\text { Jumlah } \\
\text { Siswa }\end{array}$ & $\begin{array}{c}\text { Rata- } \\
\text { rata }\end{array}$ & $\begin{array}{c}\text { Jumlah di } \\
\text { bawah KKM }\end{array}$ & $\begin{array}{c}\text { Persentase di } \\
\text { bawah KKM }\end{array}$ \\
\hline \multirow{2}{*}{$2013-2014$} & XI AP 1 & 75 & 44 & 69 & 28 & $64 \%$ \\
\cline { 2 - 7 } & XI AP 2 & 75 & 44 & 67 & 31 & $70 \%$ \\
\hline \multirow{2}{*}{$2014-2015$} & XI AP 1 & 75 & 46 & 65 & 30 & $65 \%$ \\
\cline { 2 - 7 } & XI AP 2 & 75 & 43 & 63 & 30 & $70 \%$ \\
\hline \multirow{2}{*}{$2015-2016$} & XI AP 1 & 75 & 43 & 68 & 28 & $65 \%$ \\
\cline { 2 - 7 } & XI AP 2 & 75 & 44 & 66 & 30 & $68 \%$ \\
\hline
\end{tabular}

Tabel 1 diatas menjelaskan bahwa dari tahun ke tahun hasil belajar siswa pada Mata Pelajaran Administrasi Humas dan Protokol masih rendah. Hal tersebut dapat terlihat dari banyaknya jumlah siswa yang memperoleh nilai dibawah KKM. Dari tahun ajaran 20132014 ke tahun ajaran 2014-2015 nilai rata-rata kelas XI AP 1 mengalami penurunan sebesar 4 poin, lalu kembali naik 3 poin pada tahun ajaran 2015-2016. Sedangkan pada kelas XI AP 2, dari tahun ajaran 2013-2014 ke tahun ajaran 2014-2015 mengalami penurunan rata-rata nilai kelas sebesar 4 poin dan kembali naik pada tahun ajaran 2015-2016 sebesar 3 poin. Pada tahun ajaran 2014-2015 merupakan tahun yang penurunan nilai rata-rata kelasnya paling besar yaitu sebesar 4 poin, hal tersebut terjadi baik pada Kelas XI AP 1 maupun Kelas XI AP 2. 
Faktor-faktor yang mempengaruhi hasil belajar diuraikan dalam dua bagian, yaitu faktor eksternal; faktor jasmasni, faktor psikologis, faktor kelelahan dan internal; faktor keluarga, faktor sekolah, faktor masyarakat (Slameto, 2010, hlm. 54). Salah satu upaya untuk menyelesaikan permasalahan rendahnya hasil belajar yaitu perlu diubahnya proses belajar dengan menggunakan model pembelajaran yang lebih menarik minat belajar siswa. Selain dapat meningkatkan hasil belajar, model pembelajaran juga harus mempunyai fungsi lain agar dapat diimplementasikan pada kehidupan bermasyarakat siswa.

Model pembelajaran merupakan suatu perencanaan atau suatu pola yang digunakan sebagai pedoman dalam merencanakan pembelajaran di kelas (Arends dalam Trianto, 2010, hlm.51) yang berisi prosedur sistematik (Sagala, 2010, hlm.176). Ada banyak model pembelajaran yang dapat digunakan oleh guru, salah satunya adalah model pembelajaran kooperatif. Model pembelajaran kooperatif merupakan suatu pembelajaran kelompok dengan jumlah peserta didik 2-5 orang dengan untuk saling memotivasi antara anggotanya untuk saling membantu agar tercaipainya suatu tujuan pembelajaran yang maksimal (Huda, 2011, hlm. 3) sehingga memberi kesempatan kepada siswa untuk bekerjasama dengan siswa lain dalam tugas-tugas yang terstruktur (Anita Lie, Isjoni, hlm. 15).

Model pembelajaran kooperatif merupakan model yang tepat untuk digunakan pada mata pelajaran Adm. Humas dan Protokol karena sesuai dengan output dari Mata Pelajaran tersebut yaitu agar siswa dapat memelihara kerja sama dengan masyarakat. Ada banyak tipe model pembelajaran kooperatif, salah satunya kooperatif tipe Mood, Understand, Recall, Detect, Elaborate, Review. Dalam model kooperatif tersebut, siswa dikondisikan agar berada dalam suasana hati yang baik ketika belajar. Selain itu, siswa juga dilatih untuk membaca materi pembelajaran sebelum belajar di kelas dan dapat mengungkapkan pendapat pada teman sebangkunya.

\section{TINJAUAN PUSTAKA}

\section{Model Pembelajaran Kooperatif Mood, Understand, Recall, Detect, Elaborate, Review}

Densereau (Cutis and Jill, 1991: 23) menyatakan bahwa Mood, Understand, Recall, Detect, Elaborate, Review merupakan akronim dari mengatur Mood (suasana hati) untuk belajar, Understanding (memahami) tujuan dari tugas/ materi, Recalling (mengingat) informasi yang relevan dengan meringkas poin utama, Detecting (memeriksa) kesalahan, Elaborating (menguraikan) informasi, dan (Reviewing) mengkaji ulang meteri. Pada model pembelajaran ini terdapat enam tahapan yang pada masing-masing terdapat aktivitas yang diharapkan akan membuat siswa mencapai hasil belajar yang diharapkan. Adapun langkahlangkah tersebut dijelaskan oleh Jacob (Rusdiana, 2013, hlm. 10) sebagai berikut:

\begin{tabular}{|c|c|}
\hline Mood & Create a relaxed mood, set your procedures (both members) \\
\hline Understand & Understand the section by reading silently (both members) \\
\hline Recall & Summarise the main ideas (one member) \\
\hline Detect & Listen for errors or omission in the summary (one member) \\
\hline Elaborate & $\begin{array}{l}\text { Elaborate on the ideas in the section with examples, connections, } \\
\text { opinions, reactions, applications, questions (both members) }\end{array}$ \\
\hline Review & $\begin{array}{l}\text { Summarise the entire passage after completing all the sections (both } \\
\text { members) }\end{array}$ \\
\hline
\end{tabular}


Dalam model ini, siswa dibagi ke dalam kelompok yang beranggotakan empat orang dan terdiri dari sepasang anggota dyad (sub kelompok). Jadi, pertama-tama siswa dibagi kedalam kelompok dengan jumlah 4 orang, lalu dibagi kembali menjadi 2 orang dyad 1 dan dyad 2. Pada tahap pertama siswa diatur agar dalam suasana hati (Mood) yang tepat dengan cara relaksasi dan berfokus pada tugas belajar. Tahap kedua, siswa diberikan naskah materi dan membacanya tanpa menghapalkan (Understand). Lalu tahap ketiga, dyad 1 memberikan sajian lisan dengan mengulang materi yang sebelumnya telah dibaca (Recall). Tahap keempat, dyad 2 mendengarkan dan mencocokan materi yang dibacakan dengan pemahamannya sendiri (Detect). Tahap kelima, kedua anggota dyad bersama-sama mencermati ide-de utama dari materi yang telah diberikan (Elaborate). Terakhir, pada tahap enam, kedua dyad menyimpulkan keseluruhan proses pemecahan masalah (Review).

\section{Hasil Belajar}

Hasil belajar merupakan suatu perolehan akibat dilkukannya aktivitas belajar (Purwanto, 2011, hlm. 44). Hasil belajar mempunyai peranan penting dalam proses pembelajaran karena dapat memberikan informasi kepada guru tentang perkembangan siswa dalam mencapai tujuan-tujuan belajarnya, sehingga guru dapat memberikan menyusun dan membina kegiatan-kegiatan siswa lebih lanjut. Ada tiga ranah utama dalam hasil belajar menurut Bloom (dalam Sudjana, 2006, hlm.3), yaitu ranah kognitif, afektif, dan psikomotor. Ranah yang menjadi fokus utama dalam penelitian ini adalah ranah kognitif, yaitu ranah yang menekankan kepada aspek pengetahuan dan keterampilan berpikir. Faktor-faktor yang dapat mempengaruhi hasil belajar dapat berupa faktor internal dan faktor eksternal. Faktor eksternal yang dapat berpengaruh terhadap hasil belajar diantaranya adalah kurikulum/ bajan pelajaran, guru/ pengajar, sarana dan fasilitas, administrasi/ manajemen (Purwanto, 2011, hlm 107).

\section{METODOLOGI}

Untuk mengetahui pengaruh model pembelajaran kooperatif tipe Mood, Understand, Recall, Detect, Elaborate, Review terhadap hasil belajar siswa, penulis telah melakukan penelitian dengan menggunakan Quasi Experimental Research atau metode eksperimen kuasi. Quasi Experimental Research adalah suatu metode yang dilakukan untuk memperoleh gambaran peningakatan hasil belajar. Adapun teknik pengambilan sampel yang digunakan dalam penelitian ini yaitu dengan metode Judgement sampling yaitu teknik penarikan sampel yang dilakukan berdasarkan karakteristik yang ditetapkan terhadap elemen populasi target yand disesuaikan dengan tujuan atau masalah penelitian (Muhidin dan Ating, 2011, hlm. 143).

Penelitian ini dilakukan di salah satu SMK di Kota Bandung, pada siswa Program Keahlian Administrasi Perkantoran Kelas XI AP 1 dan XI AP 2. Kedua kelas ini dipilih karena memiliki nilai capaian yang rendah dibandingkan dengan kelas-kelas AP lainnya di sekolah tersebut. Adapun jumlah siswa pada kelas eksperimen (XI AP 1) adalah sebanyak 42 orang dan kelas kontrol (XI AP 2) adalah sebanyak 44 orang.

Dalam penelitian ini, penulis menggunakan desain penelitian non equivalent control group (pre-test dan post-test yang tidak ekuivalen), pada desain ini kelompok eksperimen maupun kelompok kontrol tidak dipillih secara acak. Dua kelompok itu diberi pre-test 
kemudian diberi treatment dan yang terakhir diberikan post-test. Setelah itu, hasil dari dua kelompok tersebut dibandingkan.

Teknik pengumpulan data yang digunakan dalam penelitian ini adalah instrumen tes dan lembar observasi aktivitas guru selama dikelas. Instrumen tes terdiri dari 20 soal dengan 5 pilihan jawaban yang telah diuji validitas, reliabilitas, daya pembeda, dan tingkat kesukaran soalnya. Sementara teknik analisis data yang digunakan oleh peneliti yaitu dengan menggunakan uji normalitas, uji homogenitas, uji beda $(\mathrm{t})$, dan selanjutnya dihitung perolehan gain-nya. Lalu, perhitungan yang terakhir adalah uji hipotesis untuk mengetahui apakah ada perbedaan hasil belajar kelas eksperimen dan kelas kontrol.

\section{HASIL PENELITIAN DAN PEMBAHASAN}

Berdasrkan hasil pre-test, rata-rata nilai yang diperoleh kelas eksperimen adalah sebesar 32,0 sedangkan untuk kelas kontrol rata-rata nilai pre-test adalah 33,2. Hal tersebut menunjukan bahwa kemampuan awal kedua kelas adalah homogen. Adapun hasil rata-rata nilai post-test kelas eksperimen adalah sebesar 81,9 dan rata-rata post-test kelas kontrol adalah sebesar 73,3.

Hasil dari uji normalitas pre-test kelas eksperimen didapat nilai $\mathrm{D}_{\text {hitung }}=0,112235$ dan nilai $\mathrm{D}_{\text {tabel }}$ pada $u=0,05$ sebesar 0,136713 . Dengan demikian nilai $\mathrm{D}_{\text {hitung }}<\mathrm{D}_{\text {tabel }}$ $(0,112235<0,136713)$. Hasil ini menunjukan bahwa data variabel berdistribusi normal. Sedangkan pada uji normalitas pre-test untuk kelas kontrol didapat nilai $\mathrm{D}_{\text {hitung }}=0,107127$ dan nilai $\mathrm{D}_{\text {tabel }}$ pada $u=0,05$ sebesar 0,133570 . Dengan demikian nilai $\mathrm{D}_{\text {hitung }}<\mathrm{D}_{\text {tabel }}$ $(0,107127<0,133570)$. Hasil ini menunjukan bahwa data variabel berdistribusi normal.

Hasil dari uji normalitas post-test kelas eksperimen didapat nilai $\mathrm{D}_{\text {hitung }}=0,096036$ dan nilai $\mathrm{D}_{\text {tabel }}$ pada $u=0,05$ sebesar 0,136713 . Dengan demikian nilai $\mathrm{D}_{\text {hitung }}<\mathrm{D}_{\text {tabel }}$ $(0,096036<0,136713)$. Hasil ini menunjukan bahwa data variabel berdistribusi normal. Sedangkan pada uji normalitas post-test untuk kelas kontrol didapat nilai $\mathrm{D}_{\text {hitung }}=0,114558$ dan nilai $\mathrm{D}_{\text {tabel }}$ pada $u=0,05$ sebesar 0,133570 . Dengan demikian nilai $\mathrm{D}_{\text {hitung }}<\mathrm{D}_{\text {tabel }}$ $(0,114558<0,133570)$. Hasil ini menunjukan bahwa data variabel berdistribusi normal.

Adapun hasil uji homogenitas pada data pre-test didapat $F_{\text {hitung }}=1,028071441$ dan $F_{\text {tabel }}=1,678712991$. Sehingga dapat disimpulkan $F_{\text {hitung }}<F_{\text {tabel }}(1,028071441<$ 1,678712991), maka kedua kelas tersebut dinyatakan homogen. Sedangkan hasil uji homogenitas pada data post-test didapat $\mathrm{F}_{\text {hitung }}=1,101219512$ dan $\mathrm{F}_{\text {tabel }}=1,678712991$. Sehingga dapat disimpulkan $\mathrm{F}_{\text {hitung }}<\mathrm{F}_{\text {tabel }}(1,101219512<1,678712991)$, maka kedua kelas tersebut dinyatakan homogen.

Selanjutnya hasil uji beda atau uji-t post-test didapat nilai $t_{\text {hitung }}=4,579509231$ dan nilai $\mathrm{t}_{\text {tabel }}=1,989318521$. Dengan demikian $\mathrm{t}_{\text {hitung }}>\mathrm{t}_{\text {tabel }}(4,579509231>1,989318521)$. Hasil ini menunjukan terdapat perbedaan hasil belajar antara kelas eksperimen dan kelas kontrol.

Rata-rata Gain hasil belajar pada kelas eksperimen yang menggunakan model pembelajaran kooperatif tipe Mood, Understand, Recall, Detect, Elaborate, Review sebesar 49,88 dan nilai $N$-Gain $=0,728$. Hal tersebut menunjukan bahwa ada peningkatan hasil belajar siswa setelah pembelajaran dengan menggunakan model kooperatif tipe Mood, Understand, Recall, Detect, Elaborate, Review dan termasuk dalam kriteria Tinggi. 
Selain itu, rata-rata hasil Gain belajar pada kelas kontrol yang menggunakan model Discovery Learning adalah sebesar 40,24 dan nilai $N$-Gain $=0,591$. Hal tersebut menunjukan bahwa ada peningkatan hasil belajar siswa setelah pembelajaran dengan menggunakan model Discovery Learning dan termasuk dalam kriteria Sedang.

Pengujian hipotesis adalah langkah terakhir dalam perhitungan penelitian ini. Hasil pengujian hipotesis yang diketahui dengan uji-t adalah sebagai berikut:

Tabel 2.

Uji Hipotesis

\begin{tabular}{|c|c|c|c|c|}
\hline Kelas & $\mathbf{N}$ & $\mathbf{t}_{\text {hitung }}$ & $\mathbf{t}_{\text {tabel }}$ & Kesimpulan \\
\hline Eksperimen & 42 & 4,517905196 & 1,989318521 & $\mathrm{H}_{1}$ diterima \\
\cline { 1 - 2 } Kontrol & 44 & & & \\
\hline
\end{tabular}

Taraf kepercayaan pada penelitian ini sebesar 95\% atau alpha $=0,05$. Dari tabel diatas dapat diketahui bahwa hasil $t_{\text {hitung }}>t_{\text {tabel }}=4,517905196>1,989318521$. Sehingga dapat disimpulkan bahwa ada perbedaan hasil belajar siswa antara kelas eksperimen yang menggunakan model pembelajaran kooperatif tipe Mood, Understand, Recall, Detect, Elaborate, Review dengan kelas kontrol yang menggunakan Discovery Learning pada Mata Pelajaran Administrasi Humas dan Protokol di Kelas XI AP salah satu SMK di Kota Bandung.

Berikut adalah rangkuman pemaparan analisa statistik yang dilakukan dalam penelitian yang dilakukan penulis.

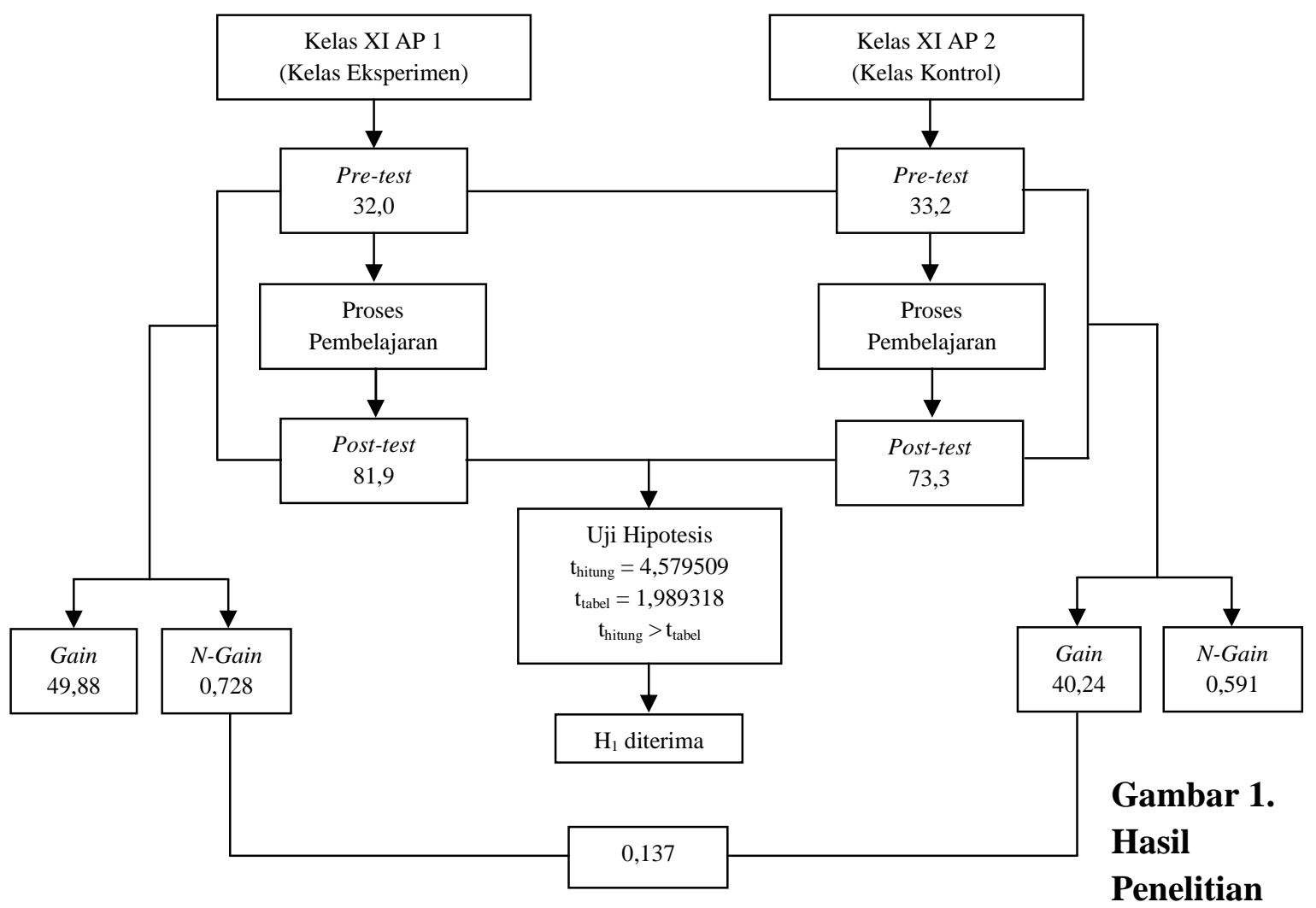




\section{KESIMPULAN}

Dari hasil pembahasan diatas dapat diambil kesimpulan bahwa terdapat perbedaan yang signifikan dari hasil belajar siswa yang menerapkan model pembelajaran kooperatif tipe Mood, Understand, Recall, Detect, Elaborate, Review di kelas eksperimen dan model Discovery Learning di kelas kontrol pada kompetensi inti Menguraikan Organisasi Profesi Humas di Kelas XI salah satu SMK di Kota Bandung. Hal ini dapat dilihat dari nilai ratarata yang diperoleh siswa kelas eksperimen lebih tinggi dibandingkan dengan kelas kontrol yang telah dijelaskan sebelumnya. Dengan begitu dapat dikatakan bahwa model pembelajaran kooperatif tipe Mood, Understand, Recall, Detect, Elaborate, Review dapat meningkatkan hasil belajar siswa. Hal tersebut dapat dijadiakn pertimbangan bagi pihak sekolah untuk dapat menerapkan model pembelajaran ini dalam upaya peningkatan hasil belajar siswa ke arah yang lebih baik lagi.

\section{DAFTAR PUSTAKA}

Cutis, J.B and Jill, S.G. (1991). Three Decades Of Cooperative Reading From Theori To Practice: Implication For The $21^{\text {st }}$ Century. A version of this paper was presented at the annual meeting of the American Educational Research Associaion, Chicago, IL. [Online]. Tersedia: https://www.scribd.com/document/2879007/CooperativeReading-review-Bonk-and-Salisbury-Glennon [13 Juni 2017]

Dimyati dan Moedjiono. (2006). Belajar dan Pembelajaran. Jakarta: Rhineka Cipta.

Huda, Miftahul. (2013). Model-model Pengajaran dan Pembelajaran. Yogyakarta: Pustaka Pelajar.

Isjoni. (2010). Cooperative Learning. Bandung: Alfabeta.

Muhidin, Sambas Ali dan Ating Somantri. (2011). Dasar-dasar Metode Statistika untuk Penelitian. Bandung: CV Pustaka Setia.

Purwanto. (2011). Psikologi Pendidikan. Bandung: PT Remaja Rosdakarya.

Rusdiana, Leli. (2013). Implementasi MURDER (Mood Understand Recall Ditect Elaborate Review) Berbantu Multimedia untuk Meningkatkan Pemahaman Konsep Siswa SMK.Bandung: Universitas Pendidikan Indonesia.

Sagala, Syaiful. (2010). Konsep dan Makna Pembelajaran. Bandung: Alfabeta.

Slameto. (2010). Proses Belajar Mengajar. Jakarta: Remaja Rosdakarya.

Sudjana, N. (2006). Penilaian Hasil Proses Belajar Mengajar. Bandung: Remaja Rosdakarya.

Syah, Muhibbin. (2008). Psikologi Pendidikan dengan Suatu Pendekatan Baru. Bandung: PT. Remaja Rosdakarya.

Trianto. (2010). Model Pembelajaran Terpadu. Jakarta: PT Bumi Aksara. 